\title{
A Comparative Study of Structural Changes in Conventional and Unconventional Machining and Mechanical Properties Evaluation of Polypropylene Based Self Reinforced Composites
}

https://doi.org/10.1515/secm-2020-0012

Received Nov 19, 2019; accepted Jan 09, 2020

Abstract: The present study addresses the mechanical behavior of polypropylene self-reinforced composites (SRC's) considering polymeric structural changes after cutting. Self-reinforced polypropylene composite is fabricated using the HOT compaction method by maintaining the processing temperature at $164^{\circ} \mathrm{C}$. Conventional and unconventional cutting methods were used to cut the samples of standard dimensions. FTIR images revealed the formation of C=C, C-F, Halogen bonds after AWJ cutting initiated a decrease in the surface roughness value to $4.5 \mu \mathrm{m}\left(\mathrm{R}_{a}\right)$. SEM analysis is performed to analyse structural integrity and damage of SRC's. Structural changes formation after AWJ cutting leads to improve the ultimate tensile strength of the laminate by $20 \%$ compared to conventional cut samples. A similar trend is noticed for flexural properties and Shore -D hardness values for the SRC composite laminate correlated to polymeric changes with Conventional cutting due to the formation of $\mathrm{C}-\mathrm{N}$ bond is observed after Laser cutting.

Keywords: Mechanical characterization, Polypropylene SRC composite, Advanced Machining, DSC, FTIR, FESEM

\section{Introduction}

Fiber-reinforced polymer (FRP) composites play a major role in distinct fields of engineering considering their excellence in stiffness and durability. FRP's have limitations like fracture toughness, low fracture strain and impact

\footnotetext{
*Corresponding Author: Padmanabhan Krishnan: SMEC, Vellore
Institute of Technology, Vellore-632014, Tamilnadu India; Email:

*Corresponding Author: Padmanabhan Krishnan: SMEC, Vello
Institute of Technology, Vellore-632014, Tamilnadu India; Email: deepa.a@vit.ac.in

Deepa A, Kuppan P: SMEC, Vellore Institute of Technology, Vellore632014, Tamilnadu India
}

ə Open Access. (๑) 2020 Deepa A et al., published by De Gruyter. (c) BY License strength. Hence, SRC composites have been designed and applied where toughness, ductility and adhesion between fibre and matrix are required [1]. Recently, polypropylene self-reinforced composites (SRC) of highly oriented crystalline fibre and matrix have been developed, it gained much attention because of its lightweight and effective mechanical characteristics [2]. Also, polypropylene SRC composites reinforced fibre and matrix belong to the same family of thermoplastic polymer, which can be recycled. Polypropylene SRC laminate can be developed and held strongly which allows the polypropylene SRC laminate to achieve high impact resistance correlated to GFRP or CFRP laminates. However crystalline fibres have a significant effect on mechanical properties which are extremely affected by the fabrication and cutting process. Hence, many researchers reported characterization based studies on the manufacturing process [3-5]. Optimizing machining parameters of SRC's also becomes a necessity to achieve the desired mechanical properties. Conventional machining processes like turning, drilling, milling and shaping have been used on polymer composites. Owing to inherent heterogeneity and anisotropy, conventional machining results in anisotropic damage of composites due to matrix cracking, fibre pull-out, delamination, etc. To improve the structural integrity of these composites, it becomes necessary to minimize the machining induced damages [6-9]. In addition, it is also suspected that some of the matrix materials and/or the reinforcements undergo structural changes due to thermal effects either due to direct heating or due to friction.

\section{Advanced Machining of SRC's}

Machining with an improved surface quality finish of composites has been narrated with advanced machining processes like abrasive water jet machining (AWJ) and laser machining. Hejjaji et al. reported that the hygroscopic na- 


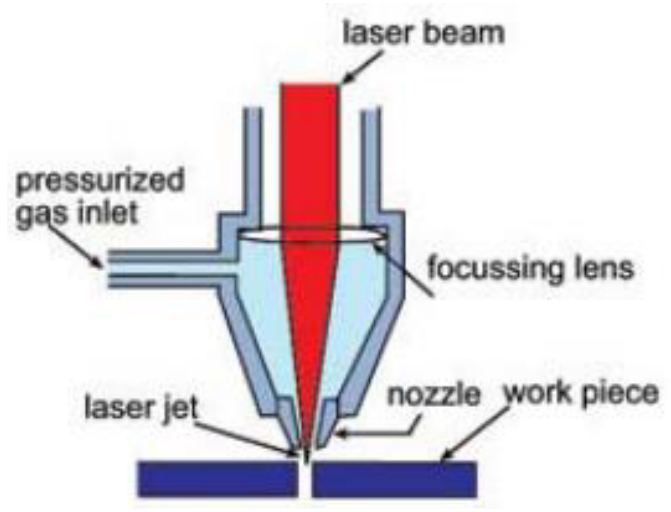

(a)

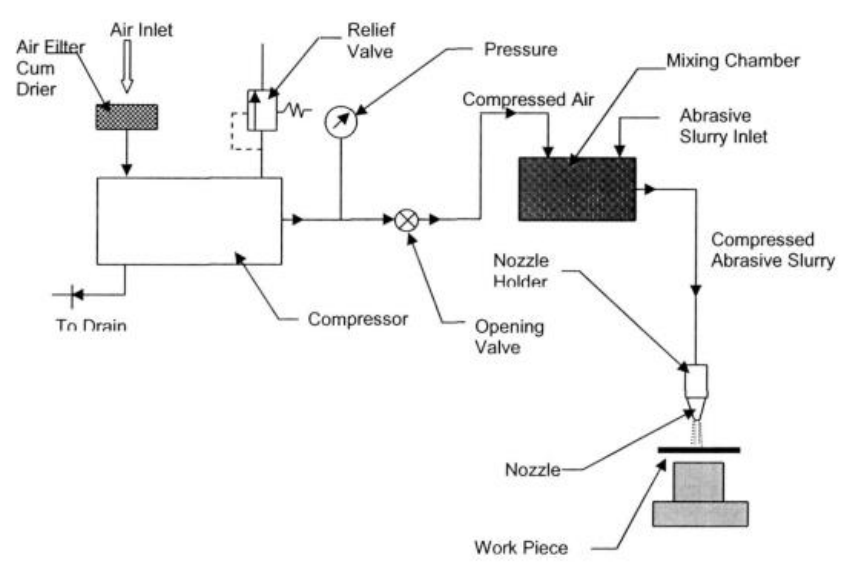

(b)

Figure 1: Diagrammatic representation of (a) Laser cutting process (b) AWJ machining

ture of the polymers and fibres, the possibility of absorption of water results in reduced strength of composite after AWJ machining [7]. Hence, Laser machining gained attention due to the non-contact nature of the tool and the possibility of dry machining mode over conventional machining. Many researchers have optimized the laser cutting parameters to get the best results for non-conventional machining for FRPs. Considerable research reports inferred that low power and high scan speed can reduce delamination during laser machining. HAZ, degradation and surface damage of SRC's generated during laser cutting were addressed.

Studies on Kevlar-polyethylene laminates machined using laser machining reported that HAZ followed an increasing trend between 0.75 to $1.7 \mathrm{~mm}$ at the entrance and 0.8 to $1.5 \mathrm{~mm}$ at the exit. The damage factor of Kevlar polypropylene and Kevlar polyethylene laminates is $\sim 1.2$ for all input energies. SEM images reported that the KPE samples matrix is quick compared to K-PP. Studies have been carried out to reduce thermal damage and heataffected zones developed during non-conventional machining $[8,9]$. LI et al. used NDYAG laser $(355 \mathrm{~nm})$ to drill carbon fibre reinforced fibres and optimized the laser machining parameters to reduce the $\mathrm{HAZ} /$ damage zone. $\mathrm{Li}$ et al. suggested shorter wavelengths to cut CFRP samples to minimize HAZ. Riverio et al. found that $540 \mu \mathrm{m} \mathrm{HAZ} \mathrm{is}$ observed using $3.5 \mathrm{~kW}$ of laser power. Hejjaji et al. found that surface roughness of laser machined laminates is high then conventionally machined samples [10-12].

\subsection{Present State of Knowledge in advanced Machining}

Advanced machining techniques improvement in mechanical properties of composites is quite successful for a wide variety of fiber composites including GFRP, Kevlar and CFRP laminates. AWJ machining and laser machining study on thermoset based composites are studied but thermos-plastic based laminates machining is lagging. Different loading parameters influence the chemical structure, morphology and thermos mechanical properties of the SRC's [13-15].

$\mathrm{CO}_{2}$ laser machining shown in Figure 1 (a) is used to reduce the electrical resistivity of PE/MNWT composite. An increase in the content of MWCNT leads to a reduction in electrical resistivity. FESEM reveals the effect of laser parameters on the resistivity of Polyethylene composite. HAZ values ranged between $0.75-1.7 \mathrm{~mm}$ and are at the entrance and 0.8 to $1.5 \mathrm{~mm}$ at outline is observed with an increase in line energy [16]. AWJT process shown in Figure 1 (b) is a better machining method for LPDE material than the conventional machining methods. Minimum ASR of $1.67 \mathrm{~lm}$ and maximum MRR $14072.02 \mathrm{~mm}^{3} / \mathrm{min}$ were obtained respectively; at optimum parameters of $5 \mathrm{~mm} / \mathrm{min}$ nozzle feed rate, $350 \mathrm{~g} / \mathrm{min}$ abrasive flow rate and $2500 \mathrm{~min}-1$ spindle speed [17-20].

\subsection{Paper Outline}

Laser machining and AWJ machining on thermoset based composites are studied but thermos-plastic based SRPC laminates cutting is rarely studied. Hence in this work, a detailed investigation of cutting induced damage of 


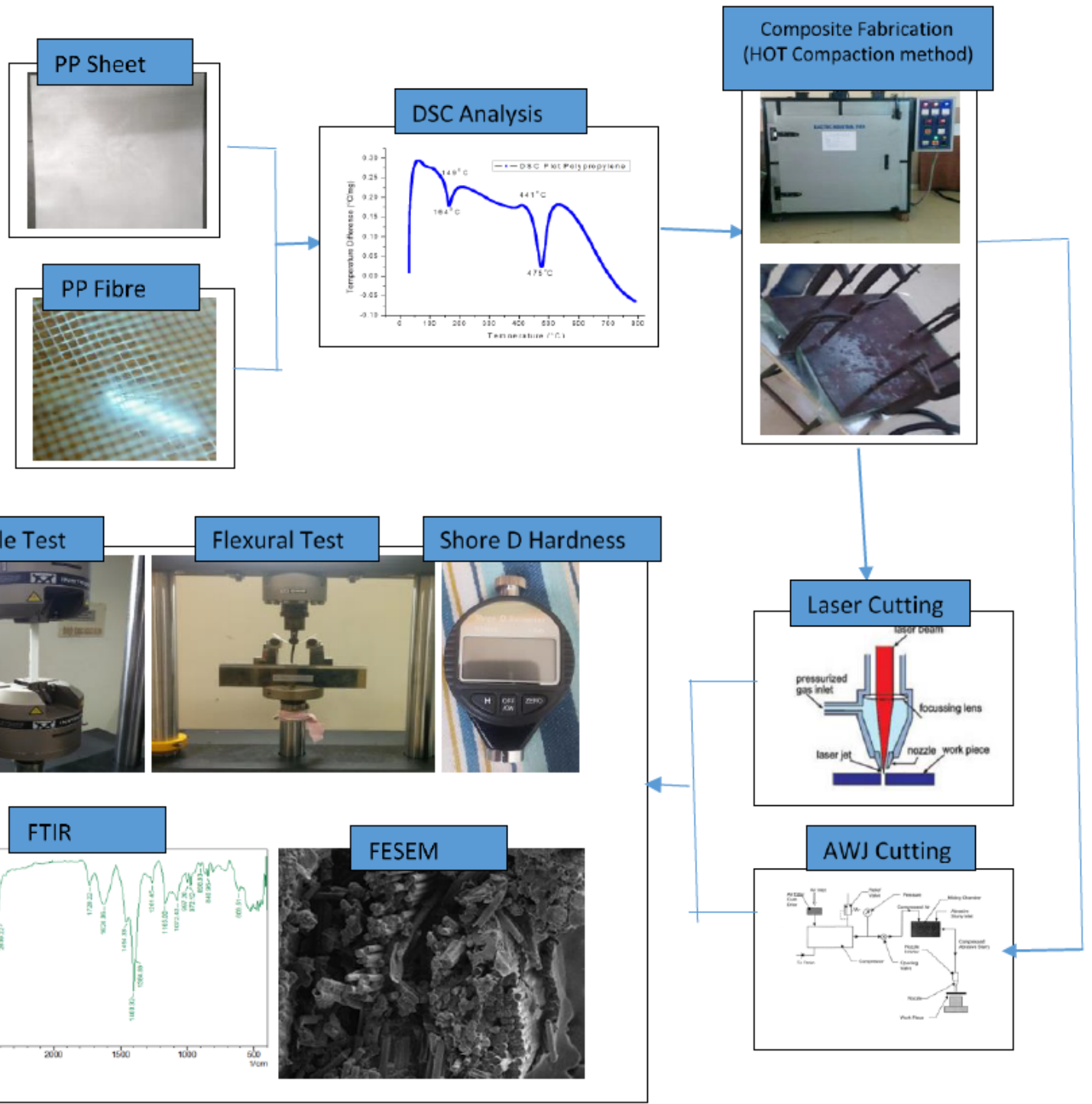

Figure 2: Schematic diagram of fabrication and testing

self-reinforced composites has been carried out considering the structural changes that accompany the cutting processes. The effect is characterized by studying the surface chemistry and morphology using Scanning Electron Microscopy. Structural integrity, elemental aspect ratios, functional groups and damage are studied using the FTIR before and after machining. In addition, Tensile tests (ASTM 638), Flexural tests and Hardness tests (Shore D)were carried out to identify the cutting induced structural changes and their influence on the mechanical properties [9].

\section{Experimental setup and measurement procedure}

\subsection{Experimental Procedure}

The entire fabrication process is shown in Figure 2. The Raw Materials Isotactic Polypropylene fiber, polypropylene matrix of $1 \mathrm{~mm}$ thickness (Korea E\&T Co.Ltd) were used to prepare laminate. Isotactic Polypropylene fibre shown in Figure 3 (a) was used to fabricate laminate under consolidated temperature The Thermogravimetric (TGA) analysis and DSC (SDT Q600 V20.9 Build 20) investigation have been employed to acquire the thermal stability (consolidated temperature)of the polypropylene fibre and 


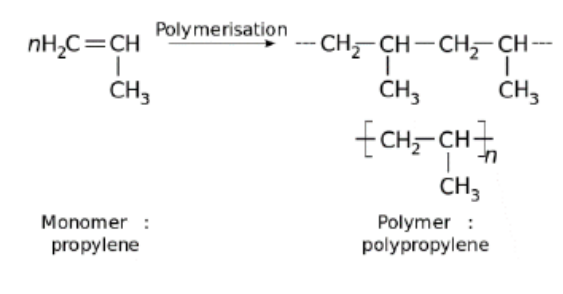

(a)

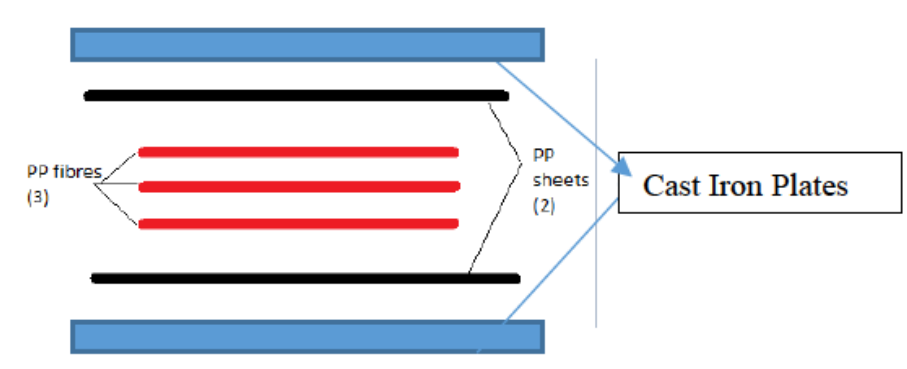

(b)

Figure 3: (a) Polymeric structure of Polypropylene (b) Schematic diagram of Fibre lay up of HOT compaction method

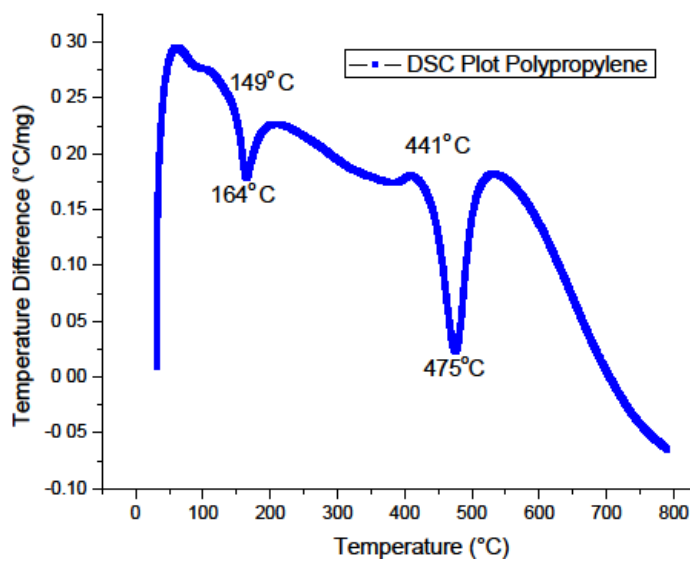

(a)

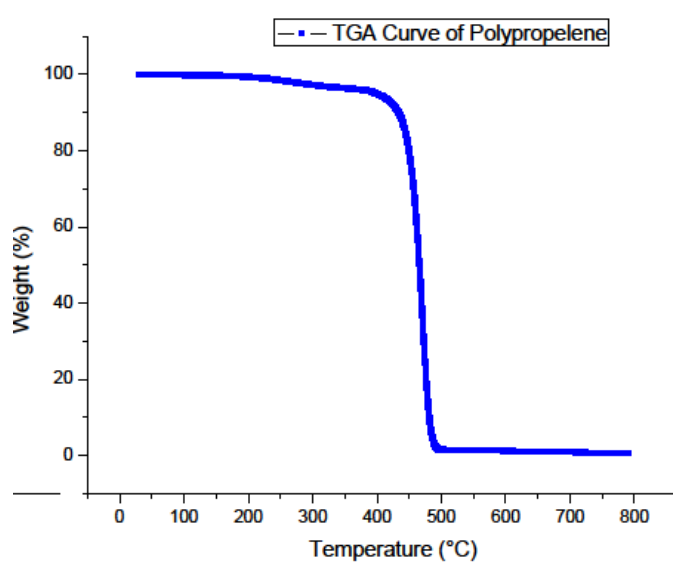

(b)

Figure 4: (a) DSC plot of Polypropylene (b) TGA plot of Polypropylene

Polypropylene matrix samples. Initial temperature, residual mass and thermal stability were determined using TGA. An analysis was implemented initially with fibre and matrix of few milligrams at elevated thermal environments from 20 to 600 degrees and DSC analysis was also carried out at the same environmental conditions. The softening temperature determined from the DSC plot is used to fabricate SRC composite using the HOT compaction method [21-23].

The laminate is prepared using three polypropylene fibers and two high-density polypropylene matrix of size $500 \mathrm{~mm} \times 500 \mathrm{~mm}$. The entire matrix and fabric layer assembly was hot compacted after slow heating to $164^{\circ} \mathrm{C}$ and held for one hour. Then the laminate was slow cooled in the oven over a few hours and de-moulded. The processing temperature for the Hot-compaction method was measured using the Differential scanning calorimetry (DSC) curve shown in Figure 4.

The hot compacted laminate samples were cut using the conventional saw and unconventional laser and Abrasive water jet (AWJ) cutting. A Laser head speed is
$420 \mathrm{~mm} / \mathrm{min}$, the laser nozzle diameter size is $1.7 \mathrm{~mm}$ and stand-off distance within the laser nozzle and the composite laminates surface was maintained at $15 \mathrm{~mm}$. The work table is CNC controlled, the focal length of the lenses is $200 \mathrm{~mm}$. The chiller unit is used to cool down the laser head and the laser source. The work area is enclosed by sliding doors. An abrasive water jet cutting system of the abrasive particle flow rate of $800 \mathrm{~g} / \mathrm{min}$ was used for cutting of Polypropylene SRC samples. The feed rate of the water jet is $1500 \mathrm{~m} / \mathrm{s}$. the stand-off distance is $4 \mathrm{~mm}$ between the surface and the nozzle. The water jet pressure of the system is maintained at 4000 bar. FESEM and FTIR spectroscopy studies were carried out to evaluate polymeric structural change, surface damage and Fibre failure.

\subsection{Measurement procedures}

The dimensions of the tensile specimens cut using conventionally and unconventionally cutting were $250 \mathrm{~mm} \times 25 \mathrm{~mm} \times 2 \mathrm{~mm}$ based on the standard ASTM D 638 . The analysis was implemented with a loading speed rate 
of $2 \mathrm{~mm} / \mathrm{min}$ using a universal testing machine (Instron 8801). The specifications of the Flexural specimen was $125 \mathrm{~mm} \times 25 \mathrm{~mm} \times 2 \mathrm{~mm}$ based on the standard ASTM D 790 M. The Flexural test was carried out in the same Instron machine at a support span length to thickness ratio of 16:1. The loading rate of the central crosshead was $2 \mathrm{~mm} / \mathrm{min}$.

Shore D Hardness Test was performed using Durometer which measures the depth of a depression developed by a force utilizing regulated presser foot on the sample. This depth is reliant on the shape of the presser foot, Visco and elastic properties, the hardness of the material. ASTM D2240 durometers are allowed to measure the primary hardness of the sample and concluding hardness after a duration of a time period [24, 25]. By applying the consistent force, without shock, hardness (depth of indentation) can be measured. Force is applied for timed hardness up till the required time and then interpret. The thickness of the material used for this analysis is $6.4 \mathrm{~mm}$ ( 0.25 inches).

\section{Results and discussion}

\subsection{Thermal stability evaluation}

The thermal stability of polypropylene fibre and matrix is investigated performing DSC and TGA analysis. DSC curves of Polypropylene obtained during the second stage of the process of heating are represented in Figure 4 (a). Transformations comprised of DSC plot show that change in enthalpy related to change of material from glassy is around $58{ }^{\circ} \mathrm{C}$, exothermic solidification at $80{ }^{\circ} \mathrm{C}$, polymer matrix softening at $164^{\circ} \mathrm{C}$ and level of crystallinity is $50 \%$ as shown in Figure 4 (a).

The TGA plot of Polypropylene exhibits density loss contour at distinct temperatures, as represented in Figure 4 (b). The initial level of density loss was observed at a range of temperatures around $30-100^{\circ} \mathrm{C}$, in representation with a weight loss of $7 \%$ of moisture. A non-oxidative thermal degradation was identified at a temperature range of $300-480^{\circ} \mathrm{C}$, which signifies the de-propagation of the Polypropylene chain. The chemical changes at the initial debonding stage of the Polypropylene chain lead to evaporation and elimination of explosive products. The deterioration of Polypropylene is increased beyond $300^{\circ} \mathrm{C}$ lead to the development of a cyclic and crosslinked design. The deterioration of Polyethylene is increased beyond $300^{\circ} \mathrm{C}$ lead to the development of cyclic and cross-linked chains. Further degradation leads to the formation of methyl ester and alkyl free radicals. A carbonize develops after $480^{\circ} \mathrm{C}$ and decay occurred at around $600^{\circ} \mathrm{C}$, remaining debris of around $1.6 \% \mathrm{w} / \mathrm{w}$ at the thermal condition of $750^{\circ} \mathrm{C}$.

\subsection{Mechanical characterization}

The influence of cutting on the Tensile strength of polypropylene SRC laminate is illustrated in Figure 5. The Ultimate tensile strength (UTS) of Polypropylene SRC laminates increased $\sim 20 \%$ after advanced cutting. This increase in tensile strength shown in Figure 5 (b) and Figure 5 (c) is probably because of the chemical changes that occurred after advanced cutting, Continuous depreciation of the hydrates enhances the tensile characteristics of the laminate. Moreover, this increasing inclination in tensile strength also results from enhancing plasticity and adhesion between the fibre and matrix due to advanced machining. Because of the formation of $\mathrm{C}-\mathrm{N}, \mathrm{C}==\mathrm{C}$ bonds after advanced cutting the tensile and flexural strengths of the polypropylene composite exhibit an improvement.

Results displayed in Figure 5 and Table 1 states that the laser cut polypropylene samples have higher load-bearing capacity compared to conventionally cut samples. In the case of ultimate tensile stress, the abrasive water cut samples exhibit a higher value than a conventionally cut sample and laser-cut sample because of the definition of cut and brittleness of the fibre. A similar trend is followed in the young's modulus. Cutting surface damage of AWJ samples is less compared to the laser cut samples. It is observed that the maximum tensile load and ultimate tensile strength of conventional samples are $1209 \mathrm{~N}$ and 21 MPa respectively. After laser cutting the ultimate tensile strength is increased to $27 \mathrm{MPa}$ due to the formation of C-N bonds which exhibit strong stretching and increased ductility compared to conventional cut samples. As the cutting definition and ductility of the sample are increased after AWJ machining, the observed formation of stiff $\mathrm{C}=\mathrm{C}$ double bonds exhibits an increase in the tensile load compared to laser machining thereby achieving a tensile strength of 30 $\mathrm{MPa} . \mathrm{C}=\mathrm{C}$ double bonds are stronger than $\mathrm{C}-\mathrm{N}$ single bonds as the bond energy of the former is $612 \mathrm{KJ} / \mathrm{mol}$ and that of the later is $315 \mathrm{KJ} / \mathrm{mol}$. The extent to which these bonds are formed also contributes to the strength [26].

Figure 6(a) infers that the flexural strength of the laser cutting is high compared to conventional cutting by $38 \%$. The aromatic and nitro bonds formation after advanced machining is the reason behind the increase in the flexural stress of the Polypropylene SRC laminate.

The flexural stress and load-bearing capacity of laser samples were $59 \mathrm{Mpa}$ and $62 \mathrm{~N}$ respectively because of the formation of $\mathrm{C}-\mathrm{O}$ bonds and $\mathrm{C}-\mathrm{N}$ bonds. Nitro Bonds ex- 

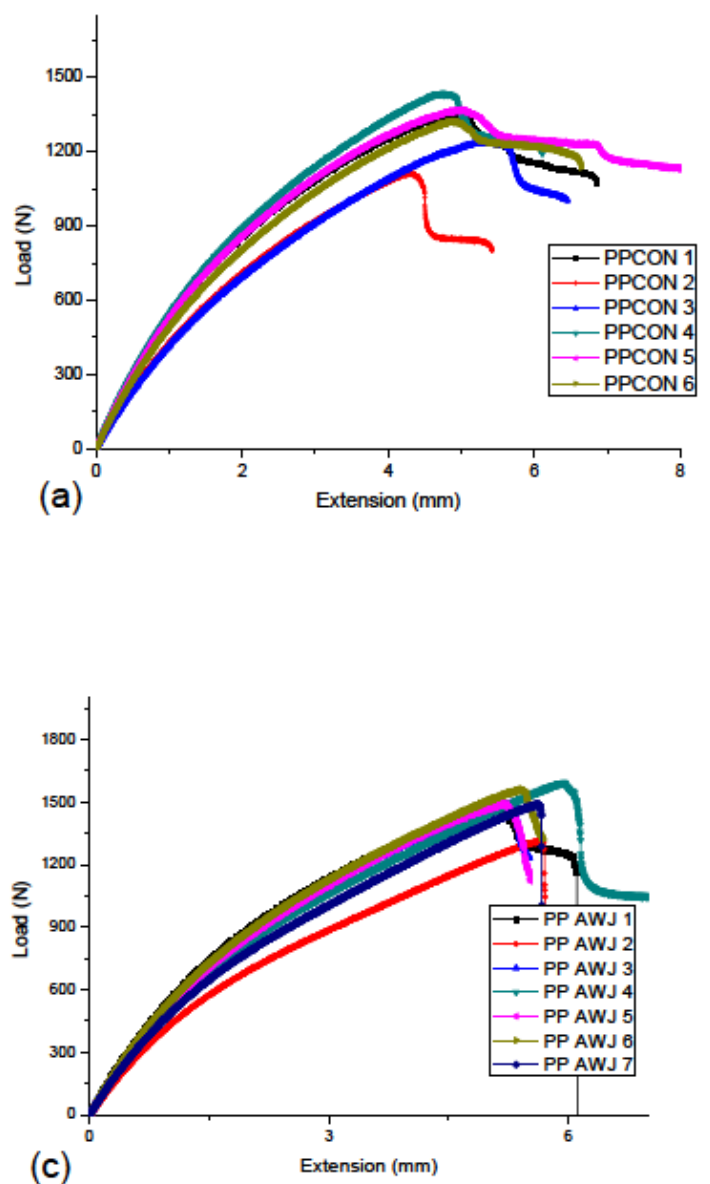

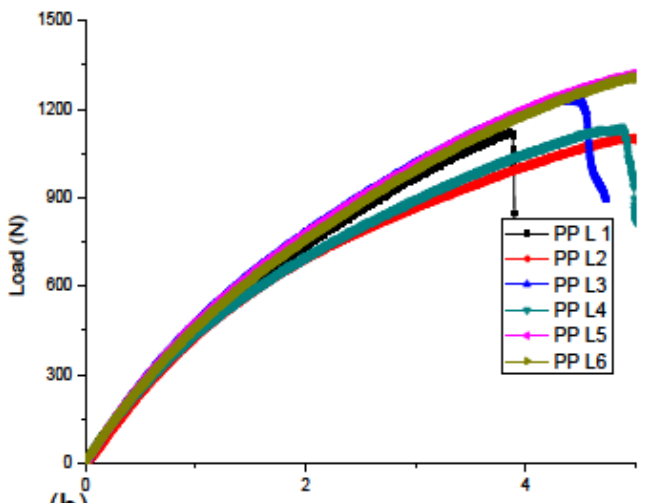

(b)

Extension (mm)

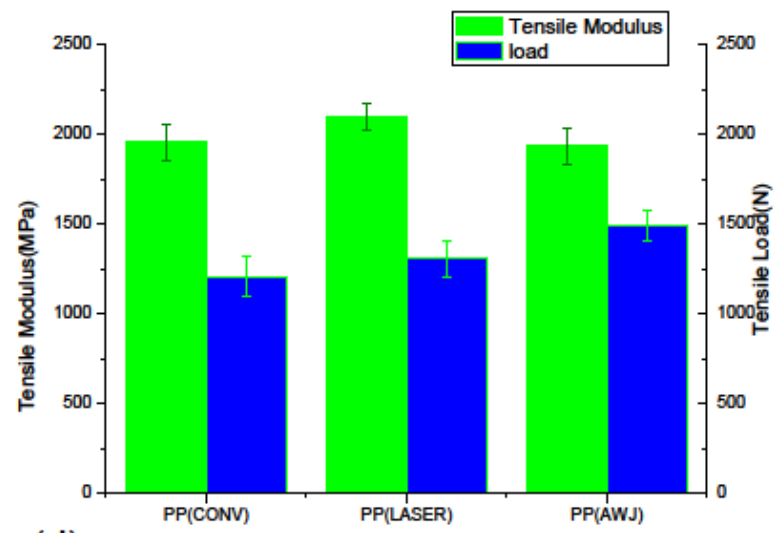

(d)

Figure 5: Tensile load plots of PP (a) Conventional samples (b) laser samples (c) AWJ samples (d) Average modulus and load plots

Table 1: Mechanical test results of Polypropylene SRC Laminate

\begin{tabular}{llllllll}
\hline $\begin{array}{l}\text { Sample } \\
\text { Name }\end{array}$ & \multicolumn{7}{l}{ Mechanical Properties Of Polypropylene SRC Laminate } \\
\hline & $\begin{array}{l}\text { Tensile Load } \\
(\mathrm{N})\end{array}$ & UTS (MPa) & $\begin{array}{l}\text { Young's } \\
\text { Modulus } \\
(\mathrm{MPa})\end{array}$ & $\begin{array}{l}\text { Flexural } \\
\text { Load (N) }\end{array}$ & $\begin{array}{l}\text { Flexural } \\
\text { Stress } \\
(\mathrm{MPa})\end{array}$ & $\begin{array}{l}\text { Flexural } \\
\text { Modulus } \\
(\mathrm{MPa})\end{array}$ & $\begin{array}{l}\text { Hardness } \\
\text { (ShoreD) }\end{array}$ \\
\hline $\mathrm{Pp}$ (Conv) & 1209 & 25 & 1956 & 38 & 37 & 1288 & 55 \\
$\mathrm{Pp}$ (Laser) & 1308 & 28 & 2096 & 61 & 59 & 2279 & 61 \\
$\mathrm{Pp}$ (Awj) & 1490 & 30 & 1937 & 59 & 57 & 2235 & 34 \\
\hline
\end{tabular}

hibiting brittleness and stiffness in the sample as shown in Figure 6. Flexural strength of the abrasive water jet samples was also high compared to conventional cut samples by $35 \%$ as a result of the formation of $\mathrm{C}=\mathrm{C}$ bonds as shown in Figure 6(a) [27].

The surface roughness values of AWJ samples are less compared to Laser-cut samples as shown in Table 2. The surface quality was observed to be good after AWJ cutting and lesser waviness was obtained compared to that of laser cutting. The abrasive water cut specimen exhibits good ductility which is the reason for low hardness. The hardness value is decreased by $48 \%$ in the AWJ cut samples as seen in Table 1. It appears that the laser cut samples thermally exhibit a temperature rise beyond the melting point of $P P$ and quench down within minutes to the ambient temperature. The zone surrounding the heat-affected zone exhibits an adiabatic characteristic as the sudden temperature rise and subsequent quenching occur within minutes. This is seen to produce an increase in hardness due to quenching effects as in martensite formation in steels. The 


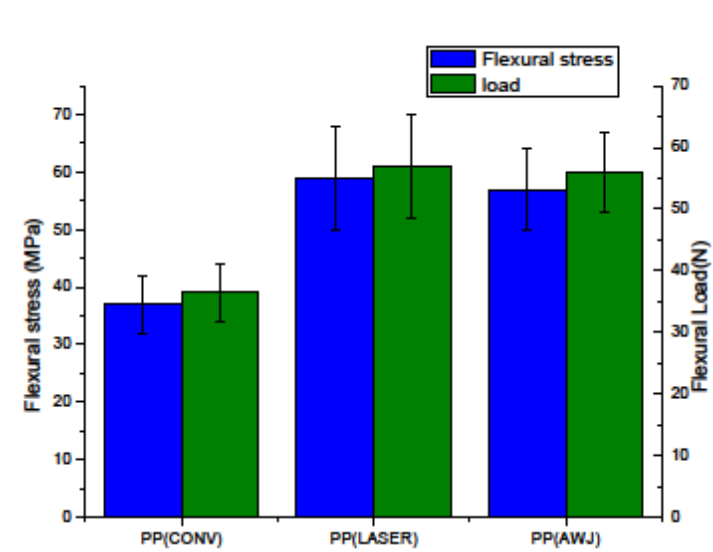

(a)

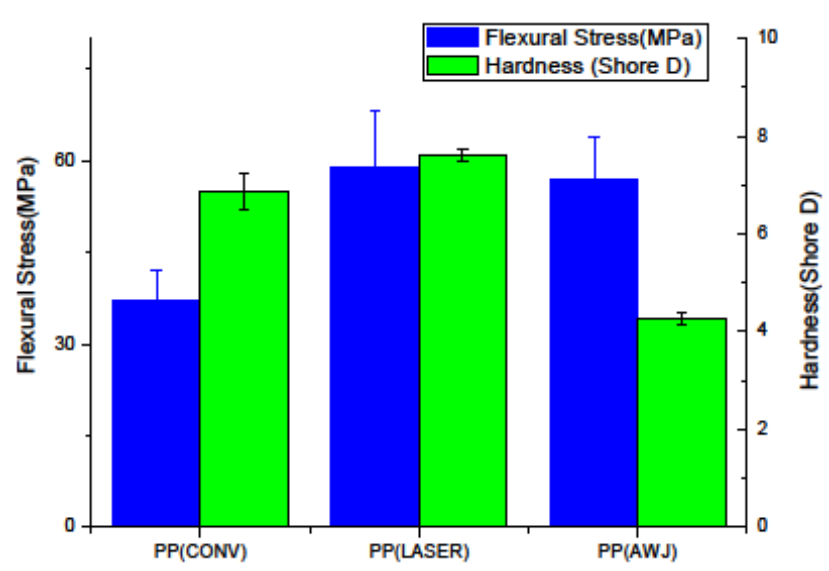

(b)

Figure 6: (a) Flexural stress and load plots (b) Hardness values of Polypropylene SRC laminate for different machining parameters

Table 2: Surface roughness measurements of Polypropylene (PP) Sample

Sample Surface roughness measurements of Polypropylene (PP) Sample

Name

\begin{tabular}{lllllll}
\hline & $\mathrm{R}_{A}(\mu \mathrm{m})$ & $\mathrm{R}_{q}(\mu \mathrm{m})$ & $\mathrm{R}_{z}(\mu \mathrm{m})$ & $\mathrm{R}_{\max }(\mu \mathrm{m})$ & $\mathrm{R}_{p}(\mu \mathrm{m})$ & $\mathrm{R}_{v}(\mu \mathrm{m})$ \\
\hline $\mathrm{PP}($ Conv $)$ & 6.7 & 7.8 & 30.6 & 33.6 & 14 & 16.5 \\
$\mathrm{PP}($ Laser $)$ & 7.76 & 9.78 & 45.35 & 51.7 & 21 & 24.3 \\
$\mathrm{PP}$ (Awj) & 4.5 & 6.5 & 20.2 & 38.7 & 10.3 & 9.9 \\
\hline
\end{tabular}

surface roughness is also seen to be higher than those of conventional or AWJ cut samples. Good mechanical properties can be associated with a smoother surface finish in the AWJ cut samples. Laser cutting is seen to be followed by a quench which is more of a reason in the improved mechanical properties than the influence of higher surface roughness.

\subsection{FT-IR Spectral analysis}

FT-IR spectroscopy of Polypropylene SRC laminate originated for conventional cut, laser-cut and abrasive water jet cut are shown in Figure 7 and Figure 8 . The band originated around $1560 \mathrm{~cm}^{-1}$ assigned for the nitro compound is missing in the polypropylene SRC laminate fabricated, but the peak gradually appeared as the laminate is cut using AWJ jet cutting as inferred from Figure 8(b). The absorption spectrum at $1730.15 \mathrm{~cm}^{-1}$ is the typical peak of Polypropylene SRC laminate which denotes the $\mathrm{C}=0$ group during conventional cutting is not visible after advanced cutting.

The absorption spectrum at $1165 \mathrm{~cm}^{-1}$ is the-C-N stretching vibration visible after laser cutting due to the

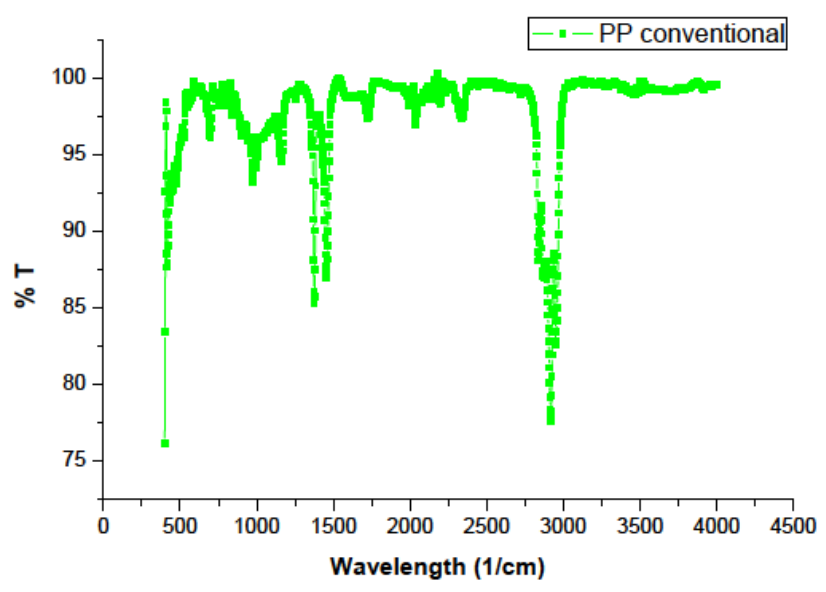

Figure 7: FTIR Plot of PP Conventional cut sample

reaction of open-air during cutting as seen in Figure 8 (a). The spectrum around $1452.40 \mathrm{~cm}^{-1}$ characterized by the bending oscillation exhibited by the covalent $(\mathrm{C}-\mathrm{H})$ chain of the methyl group. Spectra at $1579 \mathrm{~cm}^{-1}$ and $1259 \mathrm{~cm}^{-1}$ attribute to the $\mathrm{C}-\mathrm{O}$ aromatic ester and $\mathrm{N}-\mathrm{O}$ stretching. An absorption band of $972 \mathrm{~cm}^{-1}$ is visible after AWJ machining shows alkene group which exhibits strong stretching and bending vibration. The $\mathrm{C}-\mathrm{C}$ bonds have been converted 


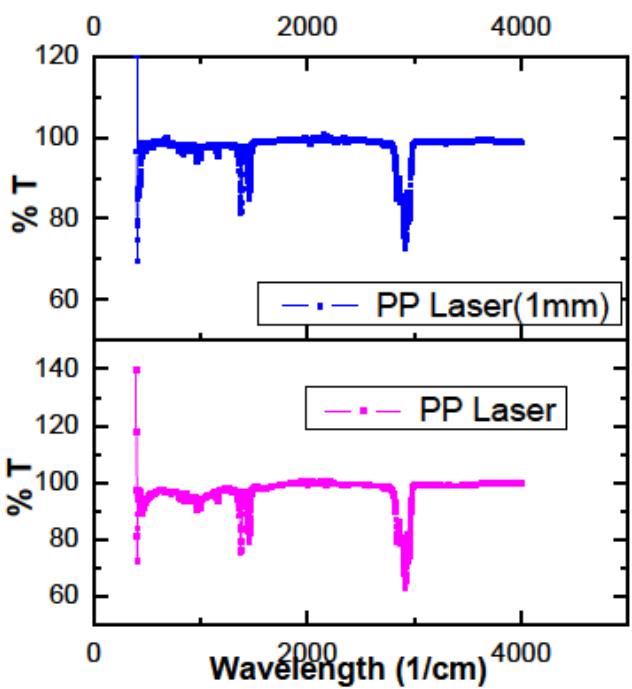

(a)

Figure 8: FTIR Images of PP (a) laser sample (b) AWJ cut sample

into different bonds like $\mathrm{C}=\mathrm{C}, \mathrm{C}=\mathrm{O}, \mathrm{C}-\mathrm{F}$ and $\mathrm{C}-\mathrm{N}$ after laser machining. The resultant bonds exhibit greater strength and stiffness than the $\mathrm{C}-\mathrm{C}$ bonds that existed before machining.

The $\mathrm{C}=\mathrm{C}$ bonds and the $\mathrm{C}=\mathrm{O}$ bonds are more than twice as strong as carbon-carbon single bonds which can be the appropriate reason for an increase in the mechanical properties. All the samples exhibit similar spectra after $\sim 1$ $\mathrm{mm}$ of case depth. Chemical interaction and reaction occur only up to $1 \mathrm{~mm}$ thickness as depicted in Figure 8. A crosssectional area for the surrounding $1 \mathrm{~mm}$ case depth of altered chemistry is seen to be responsible for the difference in mechanical properties. As tension is a cross-sectional property the percentage difference for the same sample is seen to be different compared to flexure which is due to the maximum stress in the outer fibres. A favourable chemical change at the surface would affect flexure more than tension provided the material is more brittle and less ductile. A more brittle material would show a good influence on the flexural strength but a flexible and ductile material would not benefit from a subsurface level structural change as its neutral axis would shift towards the tensile face during flexure tests, thereby reducing its strength. However, the tensile strength depends more on the cross-section of the case depth up to which a structural change is observed.

\subsection{Fractographic analysis}

Morphological studies of the polypropylene composite for different cutting conditions were shown in Figure 9. Be-

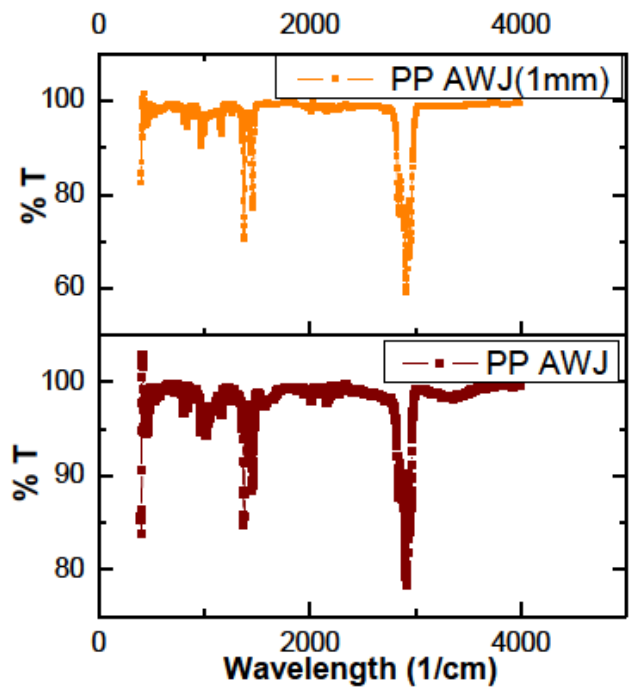

(b)

fore the advanced cutting process, PP composite had limited porosity within the composite as seen in Figure 9 (a). The gap between the PP fibre and matrix keeps them from bonding well with each other in the conventional approach. Fibre debris is low after conventional cutting. FESEM image of the Polypropylene SRC laminate laser cut sample concluded that carrying out the laser cutting process on Polypropylene SRC laminate samples improved the mechanical characteristics of the composite.

Observed occasional fibre breakage after laser cutting. PP is less ductile, but adhesion is good as shown in Figure 9 (b) and Figure 9 (c). Here, an interdiffusion of the matrix and fibre appeared to occur due to the thermal effects associated with laser cutting, these probably improve the tensile strength after laser cutting. Besides, the formation of stronger bonds as described earlier was also another reason for the improvement in strength due to laser cutting. Our own earlier supporting evidence of different polymeric systems is included in the following references [26, 27] and [28].

Also, advanced cutting exhibit chemical reactions which affect interfacial bonds and unity of the fibre to the matrix. It is noticeable from Figure 9(d) that Polypropylene SRC laminate samples exhibited the best property against delamination damage after AWJ cutting than Laser cutting. Microfiber fibrillation is a dynamic, high strain rate damage of the fibers due to dynamic cutting speeds. Where the polymer fiber absorbs the energy initiated by the cutting forces and dissipates the same by fibrillation mechanism. The single fiber axially splits into many individ- 
(a)

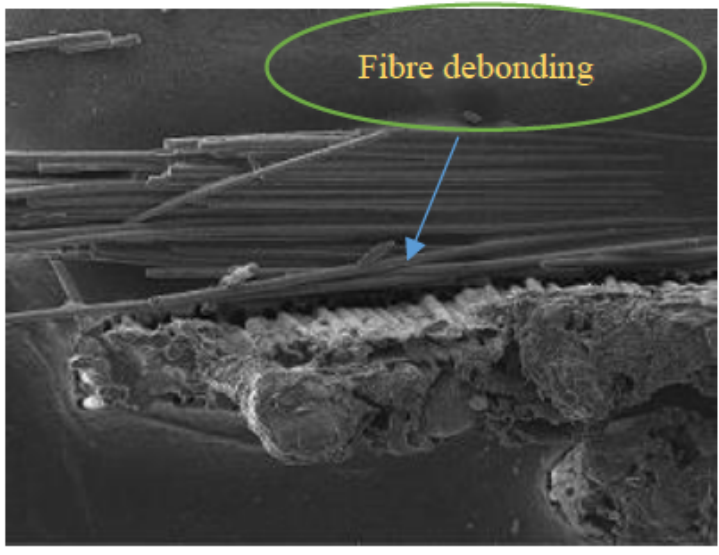

(c)

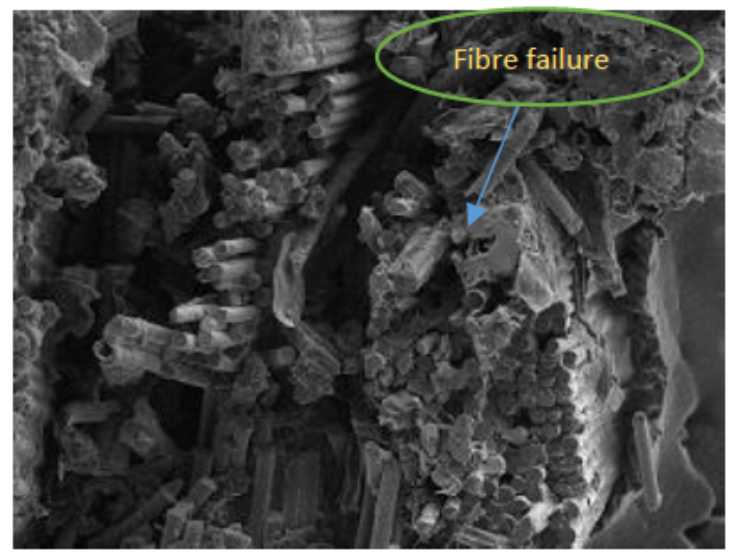

(b)

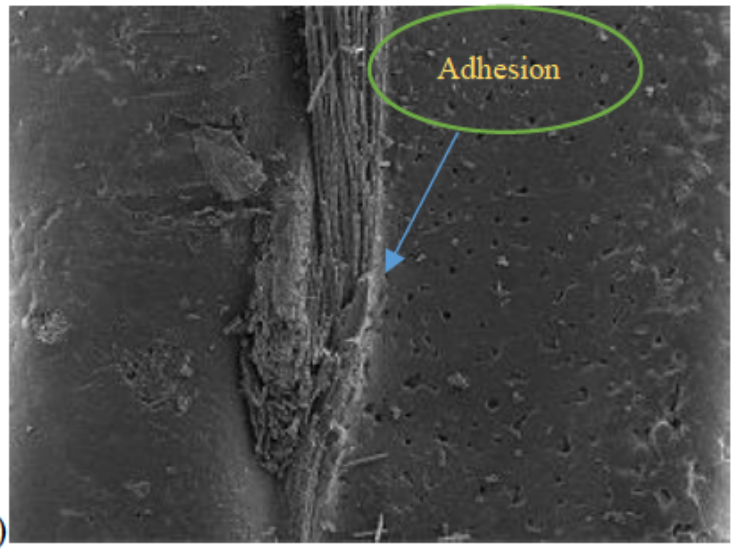

(d)

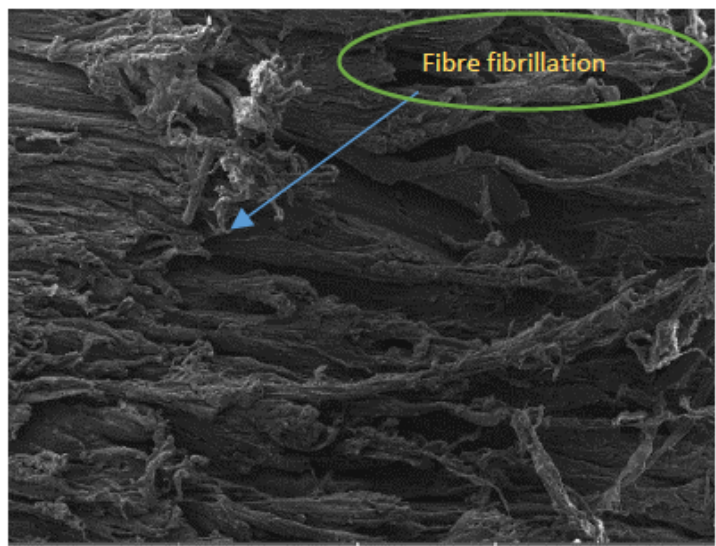

Figure 9: FESEM images of PP (a)Conventional sample (b)laser sample at 100X Magnification (c)laser sample at 500X Magnification factor (d) AWJ sample

ual fragments which are described as fibrillation. This was observed to a large extent in the AWJ cutting due to the high localized cutting force. The surface finish of brittle materials was exhibiting low roughness values as the laminate fracture was sharp, smooth, straight perpendicular, whereas ductile materials exhibit good surface finish with the broom, rough fracture.

\section{Conclusion}

The objective of this attempt was the preparation and analysis of Polypropylene SRC laminate samples using different cutting methods. The strength of the sample depends strongly on the cutting which was confirmed experimentally. The influence of the advanced cutting on polypropylene SRC has been investigated experimentally. This is an innovative investigation for the assistance of researchers and polymer industries such as aerospace, automobile, electronics and marine. Interpreted conclusions based on analysis done are as follows:
- A non-oxidative thermal degradation identified at a temperature range of $300-480^{\circ} \mathrm{C}$ signifies the degeneration till the termination of the Polypropylene bond. The degradation of Polypropylene is increased above $300^{\circ} \mathrm{C}$ lead to the development of cyclic and crosslinked structures. Further degradation leads to the formation of methyl ester and alkyl free radicals. A carbonize develops after $480^{\circ} \mathrm{C}$ and decay occurred at around $600^{\circ} \mathrm{C}$, remaining debris of around $1.6 \% \mathrm{w} / \mathrm{w}$ at the thermal condition of $750^{\circ} \mathrm{C}$.

- $\mathrm{N}-\mathrm{O}$ stretching and C-O stretching aromatic ester, absorptions are visible after AWJ cutting shows alkene group which exhibits strong stretching and bending vibration. The $\mathrm{C}$ - $\mathrm{C}$ bonds have been converted into different bonds like $\mathrm{C}=\mathrm{C}, \mathrm{C}=\mathrm{O}, \mathrm{C}-\mathrm{F}$ and $\mathrm{C}-\mathrm{N}$ after laser cutting. The carbon-carbon double bonds and the $\mathrm{C}=\mathrm{O}$ bonds are more than twice as strong as $\mathrm{C}=\mathrm{C}$ bonds which can be the appropriate reason for an increase in the mechanical properties. 
- Advanced machining exhibit distinct chemical reactions which affect the interfacial bond strength of the laminate. It is clearly visible that Polypropylene SRC laminate samples showed the enhanced property against damage due to delamination after AWJ cutting than Laser machining and conventional cutting. Occasional fibre breakage and good adhesion between fibre and matrix are observed after laser cutting due to heat-induced fusion and interdiffusion. Quenching after laser heating also contributes to higher levels of hardening and hardness values.

- The tensile strength of all composites increased after advanced cutting by $20 \%$. Degradation of the hydrates provides an enhancement in tensile strength of the composites. ultimate tensile stress (30MPa) of the abrasive water cut samples have been gained prominence as it is better than a conventionally cut sample and laser-cut sample. The flexural strength of the laser cut sample is high compared to conventional cutting by $38 \%$, the abrasive water jet samples also gained prominence related to conventional cutting by $35 \%$ as a result of the formation of $\mathrm{C}=\mathrm{C}$ bonds.

- In cutting Polypropylene composite with AWJ cutting, quality surface finish and low surface waviness are obtained compared to laser cutting, even though it is a thermoplastic material. The hardness value of the abrasive water jet sample is less compared to laser cut and conventionally cut samples by $48 \%$ because of the formation of stretched bonds after the pressurised abrasive water flow.

Finally, the forthcoming scope of works will explore to acknowledge the effects of the advanced machining for different processing temperate using the HOT compaction method. Drilling-induced damage for the respective processing temperature of Polypropylene SRC laminate samples with enhanced mechanical properties is also hereby proposed.

\section{References}

[1] Hwang YT, Kang SY, Kim DH, Kim HS. The influence of consolidation temperature on in-plane and interlaminar mechanical properties of self-reinforced polypropylene composite. Compos Struct. 2019;210:767-77.

[2] Chouhan H, Singh D, Parmar V, Kalyanasundaram D, Bhatnagar $\mathrm{N}$. Laser machining of Kevlar fibre reinforced laminates-Effect of polyetherimide versus polypropylene matrix. Compos Sci Technol. 2016;134:267-74.
[3] Brzozowska-Stanuch A, Rabiej S, Fabia J, Nowak J. Changes in thermal properties of isotactic polypropylene with different additives during aging process. Polimery. 2014;59(4):302-7.

[4] Das DK, Mishra PC, Singh S, Pattanaik S. Fabrication and heat treatment of ceramic-reinforced aluminium matrix composites-a review. International Journal of Mechanical and Materials Engineering. 2014;9(1):6.

[5] Bahari SA, Grigsby W, Krause A. Thermal stability of processed $\mathrm{PVC} /$ bamboo blends: effect of compounding procedures. Eur J Wood Wood Prod. 2017;75(2):147-59.

[6] Hejjaji A, Singh D, Kubher S, Kalyanasundaram D, Gururaja S. Machining damage in FRPs: laser versus conventional drilling. Compos, Part A Appl Sci Manuf. 2016;82:42-52.

[7] Dhakal HN, Ismail SO, Ojo SO, Paggi M, Smith JR. Abrasive water jet drilling of advanced sustainable bio-fibre-reinforced polymer/hybrid composites: a comprehensive analysis of machininginduced damage responses. Int J Adv Manuf Technol. 2018;99(912):2833-47.

[8] Mohammadi F, Zinati RF, Fattahi AM. The effect of CNC and manual laser machining on electrical resistance of HDPE/MWCNT composite. Int Nano Lett. 2018;8(2):137-45.

[9] Salama A, Mativenga P, Li L. (2012, September). Tea CO2 laser machining of carbon fiber-reinforced polymer composites. In International Congress on Applications of Lasers \& Electro-Optics (Vol. 2012, No. 1, pp. 302-308). LIA.

[10] Saha D, Majumdar MK, Das AK, Chowdhury AM, Ashaduzzaman M. Structural Nanocomposite Fabrication from Self-Assembled Choline Chloride Modified Kaolinite into Poly (Methylmethacrylate). Journal of Composites Science. 2019;3(3):83.

[11] Barczewski M, Matykiewicz D, Krygier A, Andrzejewski J, Skórczewska K. Characterization of poly (lactic acid) biocomposites filled with chestnut shell waste. J Mater Cycles Waste Manag. 2018;20(2):914-24.

[12] Zhang Z, Yao X, Zhu H, Hua S, Chen YL. Preparation and mechanical properties of polypropylene fiber reinforced calcined kaolin-fly ash based geopolymer. J Cent South Univ Technol. 2009;16(1):49-52.

[13] ASTM D638-10. Standard test method for tensile properties of plastics. West Conshohocken: ASTM International; 2010.

[14] ASTM D790-10. Standard test methods for flexural properties of unreinforced and reinforced plastics and electrical insulating materials. West Conshohocken: ASTM International; 2010.

[15] Barczewski M, Matykiewicz D, Krygier A, Andrzejewski J, Skórczewska K. Characterization of poly (lactic acid) biocomposites filled with chestnut shell waste. J Mater Cycles Waste Manag. 2018;20(2):914-24.

[16] Datta J, Kosiorek P, Włoch M. Effect of high loading of titanium dioxide particles on the morphology, mechanical and thermomechanical properties of the natural rubber-based composites. Iran Polym J. 2016;25(12):1021-35.

[17] Kord B, Ravanfar P, Ayrilmis N. Influence of organically modified nanoclay on thermal and combustion properties of bagasse reinforced HDPE nanocomposites. J Polym Environ. 2017;25(4):1198207.

[18] Cordin M, Bechtold T, Pham T. Effect of fibre orientation on the mechanical properties of polypropylene-lyocell composites. Cellulose. 2018;25(12):7197-210.

[19] Nizamuddin S, Jadhav A, Qureshi SS, Baloch HA, Siddiqui MT, Mubarak NM, et al. Synthesis and characterization of polylactide/rice husk hydrochar composite. Sci Rep. 2019 Apr;9(1):5445. 
[20] Xin, X., Liu, L., Liu, Y., \& Leng, J. Mechanical Models, Structures, and Applications of Shape-Memory Polymers and Their Composites. Acta Mechanica Solida Sinica, 1-31.

[21] Alomayri T, Vickers L, Shaikh FU, Low IM. Mechanical properties of cotton fabric reinforced geopolymer composites at 200-1000 C. Journal of Advanced Ceramics. 2014;3(3):184-93.

[22] Baran I, Cinar K, Ersoy N, Akkerman R, Hattel JH. A review on the mechanical modeling of composite manufacturing processes. Arch Comput Methods Eng. 2017;24(2):365-95.

[23] Dudarev A, Volegov K, Kurzanov G. Rheonomic phenomenon shrinkage of holes drilled in fibreglass and carbon fibrereinforced polymer composites. Mech Adv Mater Mod Process. 2017;3(1):17.

[24] Watanabe R, Hagihara H, Sato H. Structure-property relationships of polypropylene-based nanocomposites obtained by dispersing mesoporous silica into hydroxyl-functionalized polypropylene. Part 1: toughness, stiffness and transparency. Polym J. 2018;50(11):1057-65.
[25] Rajamohan V, Mathew AT. Material and Mechanical Characterization of Multi-Functional Carbon Nanotube Reinforced Hybrid Composite Materials. Exp Tech. 2019;43(3):301-14.

[26] Deepa A, Padmanabhan K, Kuppan P. Impact On Structural And Mechanical Properties Of Composites During Machining And Cutting: A Review. J Eng Appl Sci (Asian Res Publ Netw). 2006;11(17):10305-14.

[27] Deepa A, Padmanabhan K, Kuppan P. Machining and characterization of self-reinforced polymers. IOP Materials Science and Engineering Conference Series. 2017;263(6):1-9.

[28] Deepa A, Padmanabhan K, Kuppan P. Analysis and optimization of machining parameters of laser cutting for polypropylene composite. IOP Materials Science and Engineering Conference Series. 2017;263(6):1-9. 